\title{
Rugoscopia palatina e a aplicabilidade na identificação humana em odontologia legal: revisão de literatura
}

\section{Palatal rugae and applicability in human identification in forensic dentistry: literature review}

\author{
Denise Cremonezzi Tornavoi ${ }^{1}$, Ricardo Henrique Alves da Silva²
}

Tornavoi DC, Sllva RHAD. Rugoscopia palatina e a aplicabilidade na identificação humana em odontologia legal: revisão de literatura. Saúde Ética \& Justiça. 2010; 15(1):28-34.

Resumo: As rugosidades palatinas são formadas no $3^{\circ}$ mês de vida intra-uterina e permanecem na mesma posição durante toda a vida, possuindo resistência à ação destrutiva, uma vez cobertas pelas estruturas dentais e esqueléticas. Apresentam uma grande variabilidade anatômica, sendo assimétricas na espécie humana, o que diferencia os humanos dos demais mamíferos, individuais, imutáveis, perenes e passíveis de serem classificadas, requisitos fundamentais para a identificação humana, viabilizando sua utilização em ocasiões em que os métodos classicamente estabelecidos são inviáveis. Essa ferramenta da Antropologia Forense pode ser aplicada tanto no cadáver recente como no indivíduo vivo e são várias as formas e sistemas de classificações existentes. Assim, o objetivo do presente trabalho é, por meio de uma revisão de literatura, apresentar a importância deste recurso e os diferentes sistemas de classificação existentes. Conclui-se que a técnica de identificação por meio da rugosidade palatina é viável, mas, apesar de ser simples, por não exigir qualquer instrumentação complexa, deixa de ser utilizada por desconhecimento dos profissionais.

DesCRITORES: Odontologia legal; Rugosidade palatina; Identificação humana; Antropologia forense.

INTRODUÇÃO

ए ntre os métodos mais comuns que permitem uma identificação humana rápida e segura, encontram-se a análise dos arcos dentais, a datiloscopia e as comparações de DNA. No entanto, em certas ocasiões, a utilização de tais técnicas não é viável, e, então, algumas menos utilizadas, tais como a queiloscopia e a rugoscopia palatina, que, devido às suas características, podem ser aplicadas com êxito na identificação humana ${ }^{2}$.

A técnica de identificação que utiliza as rugosidades do palato foi proposta na década de 1930 pelo pesquisador espanhol Trobo-Hermosa, sendo melhor estudada por outros pesquisadores nos anos seguintes. Pelo fato das rugosidades palatinas serem imutáveis durante toda a vida do indivíduo, desde antes do nascimento até certo período após a morte, esta é uma metodologia de identificação que apresenta, mesmo em

\footnotetext{
1 Aluna de Graduação - Faculdade de Odontologia de Ribeirão Preto - USP.

2 Doutor - Odontologia Legal - Faculdade de Odontologia de Ribeirão Preto - USP.

Endereço para correspondência: Prof. Dr. Ricardo Henrique Alves da Silva. Faculdade de Odontologia de Ribeirão Preto-USP. Departamento de Clínica Infantil, Odontologia Preventiva e Social. Avenida do Café, s/n, Bairro Monte Alegre, Ribeirão Preto, SP, CEP: 14040-904. E-mail: ricardohenrique@usp.br
} 
condições desfavoráveis, eficiência na sua utilização.

Assim, o objetivo do presente trabalho é apresentaraimportânciaediferentesmetodologiase sistemas de classificação referentes à rugoscopia palatina, por meio de estudo da literatura, sendo a seleção de artigos realizada a partir de busca na Biblioteca Virtual em Saúde (BVS), a partir de descritores (antropologia forense, identificação humana, rugosidade palatina, odontologia legal, palato, rugas), tanto em língua portuguesa quanto inglesa. O critério de inclusão baseou-se na seleção de artigos referentes ao tema e sem limite temporal. E, além da referida base de dados, também foram pesquisados livros, dissertações e teses na temática do estudo, enfocando as áreas de Odontologia Legal e Medicina Legal.

IDENTIFICAÇÃO HUMANA

O processo cuja finalidade é levantar uma identidade chama-se identificação, ela pode ser realizada por técnicos treinados ou por profissionais com conhecimentos diferenciados e específicos ${ }^{18}$, e consiste na comparação dos caracteres, procurando as coincidências entre os dados previamente registrados e os obtidos no presente. E a identificação pessoal pode ser realizada tanto em indivíduos vivos quanto após o óbito, em suas mais diversas condições (conservados, em decomposição, carbonizados, esquartejados, mutilados e fragmentados) $)^{12}$.

Para que uma identificação técnica seja aplicável, alguns princípios devem ser considerados ${ }^{9}$ : Unicidade ou individualidade (apenas um único indivíduo pode conter determinados elementos que devem ser diferentes nos demais); Imutabilidade (os atributos não se alteram com o passar do tempo); Perenidade (persiste à ação do tempo); Praticabilidade (o processo de obtenção de registro dos caracteres deve ser de fácil aplicação e o custo, viável); Classificabilidade (é fundamental manter arquivado os registros obtidos, dessa forma, a possibilidade de classificação facilitará o arquivamento e a rapidez na busca dos dados).

A ODONTOLOGIA LEGAL E A IDENTIFICAÇÃO HUMANA

Nos casos em que é necessário realizar a identificação de corpos que se encontram carbonizados, decompostos, esqueletizados, mutilados ou fragmentados por qualquer razão, é extremamente comum a dentição ser a única fonte de informação para esta investigação. Conforme salienta Sopher26: "Um dos aspectos irônicos do mundo natural é que a dentição humana, local de decomposição prevalente e crônica em vida, dura mais que todos os outros tecidos após a morte".

De acordo com Galvão ${ }^{10}$, em situações de identificação cadavérica, quando se dispõe da ficha odontológica do desaparecido, é perfeitamente possível sua identificação pela comparação do odontograma do cadáver com o fornecido pelo cirurgião-dentista da pessoa desaparecida, pois a boca permite uma infinidade de possibilidades por possuir características distintivas ${ }^{4}$. Assim, define-se que a Odontologia Legal constitui, a rigor, um dos ramos da Medicina Legal ${ }^{30}$, como especialidade que aplica os conhecimentos odontológicos, desde anatomia e matérias básicas, até as mais complexas especialidades, aos interesses da Justiça e do Direito ${ }^{24}$.

Para a realização da técnica odontolegal é fundamental a existência de uma documentação produzida em função de atendimento odontológico, que normalmenteécompostapeloprontuárioodontológico, radiografias, modelos de gesso, fotografias, dentre outras. Por se tratar de uma metodologia comparativa, é dividida em três etapas: exame dos arcos dentais do cadáver, exame da documentação odontológica e confronto odontolegal ${ }^{23}$.

Dessa forma, através de uma avaliação preliminar, exame post-mortem e ante-mortem, e comparações, o odontolegista pode desenvolver todas as informações necessárias para chegar a uma conclusão sobre a identidade de um indivíduo ${ }^{13,20}$. Para a verificação da identidade, o confronto de marcas de mordidas deixadas em alimentos, ou mesmo na pele de suas vítimas com os arcos dentários ${ }^{8}$, no caso de suspeitos, manchas de saliva, características diferenciais da dentição entre espécies e sexos, são alguns dos outros métodos possíveis.

Neste contexto, entre os métodos mais comuns que permitem uma identificação humana rápida e segura, encontram-se a análise dos arcos dentais, a datiloscopia e as comparações de DNA. No entanto, em certas ocasiões, tais técnicas não podem ser utilizadas, surgem, então, 
Tornavoi DC, Silva RHAD. Rugoscopia palatina e a aplicabilidade na identificação humana

técnicas acessórias, tais como a queiloscopia e a rugoscopia palatina, que podem ser utilizadas com êxito na identificação humana ${ }^{1}$.

\section{RUGOSCOPIA PALATINA}

Quando a vítima não tem dentes, os métodos disponíveis na Odontologia Legal para identificação são mais limitados. Entre os elementos de prova retirados de uma vítima desdentada, as rugosidades palatinas são uma das únicas e facilmente obteníveis características morfológicas, cujo padrão pode ser tomado não só diretamente a partir do palato duro, mas, também, a partir da superfície mucosa das dentaduras ${ }^{17}$.

A rugoscopia palatina é o estudo das pregas palatinas (forma, tamanho e posição), que tem como finalidade estabelecer a identidade, sendo possível sua aplicação tanto no cadáver recente, como no indivíduo vivo. Vale ressaltar, ainda, que esta técnica não é útil na investigação de suspeitos na cena de um crime, visto que neste contexto não se espera encontrar este tipo de prova. Outra limitação, de acordo com Gitto et al. ${ }^{11}$, consiste no fato de que, a fim de melhorar os padrões de expressão e adaptação de próteses totais superiores, rugas e/ou ranhuras são incorporadas ao aparelho, o que inviabiliza a técnica de comparação para a identificação.

O potencial para a identificação da cavidade oral é tão grande que alguns consideram a boca como sendo "a caixa preta do corpo" ${ }^{\text {. Não só os }}$ dentes e ossos maxilares são úteis para o trabalho de identificação, mas também as estruturas de tecidos moles como os lábios e o palato duro, especialmente este último que, por ser coberto pelas estruturas dentárias e esqueléticas, apresenta maior resistência à ação destrutiva em comparação com os outros tecidos moles'.

\section{DESENVOLVIMENTO E MANUTENÇÃO DAS RUGAS PALATINAS}

A superfície da mucosa oral é, em sua maioria, lisa, sem sulcos ou cristas, mas apresenta algumas exceções, como na porção anterior da mucosa palatina, onde está presente um denso sistema de rugas, próximo à papila, atrás dos incisivos centrais $^{30}$. As rugas palatinas são formadas no terceiro mês de vida intra-uterina e não sofrem qualquer alteração, exceto de comprimento, devido ao crescimento e desenvolvimento do palato, da infância à idade adulta, permanecendo na mesma posição durante toda a vida ${ }^{4,13}$.

Acredita-se que nem mesmo doenças, traumatismos e agressões químicas possam promover mudanças na forma das rugas palatinas e que quando alterações são observadas, são menos acentuadas que nos demais órgãos ${ }^{17}$. Estudos comprovam que, frente à alteração decorrente da utilização de disjuntor palatino, elas mantêm padrões constantes, preenchendo os requisitos para identificação humana². No entanto, alguns eventos podem contribuir para mudanças em seu padrão, como a extrema sucção do dedo na infância e a constante pressão por ocasião de tratamento ortodôntico ${ }^{14}$. Ainda é comprovado que a rugosidade palatina apresenta capacidade de resistir às mudanças promovidas pela decomposição por até sete dias após a morte ${ }^{15}$.

\section{Aspectos ANATÔMICOS}

Anatomicamente, na mucosa do palato duro, identificam-se a rafe palatina, um sulco ânteroposterior, central, limitado por um conjunto de cristas lineares; as rugosidades palatinas, originárias do tecido conjuntivo denso da submucosa, fibrosas, que variam de três a cinco para cada lado. Com o aumento no tamanho da parte anterior do palato, nos primeiros anos de vida, o comprimento das rugas e a distância entre elas aumentam de forma que seu padrão de orientação torna-se mais claro6. As rugas palatinas posteriores ficam aquém da metade anterior do palato duro e nunca cruzam a linha mediana, e as anteriores, sendo geralmente mais proeminentes do que as posteriores. De um modo geral, dois terços das rugas são curvas e o restante é angular ${ }^{28}$.

A configuração, o comprimento, a largura, o número e a orientação variam consideravelmente entre as pessoas, até mesmo entre gêmeos monozigóticos. Esta variação também existe, embora em menor grau, entre os dois lados em uma mesma pessoa ${ }^{12}$. O conjunto dessas cristas é espécie-específico, sendoassimétriconos humanos, o que os diferencia dos demais mamíferos, cujas rugosidades são simétricas ${ }^{21}$. 
FUnÇÃO DAS RUGAS PALATINAS

As rugosidades palatinas cumprem na cavidade bucal algumas funções como4:

a) Facilitar o transporte dos alimentos através da cavidade oral;

b) Evitar perda de alimento da boca;

c) Participar na mastigação, percepção gustativa e tátil devido à presença de receptores;

d) Reter a saliva, que é um componente importante para a digestão inicial dos alimentos devido à presença de enzimas responsáveis pela hidrólise;

e) Auxiliar na trituração dos alimentos;

f) Proteger a mucosa do palato de traumas provocados por alimentos duros ou fibrosos;

g) Desempenhar papel na fonação, visto que dispersa as ondas sonoras em diferentes direções, o que confere timbre e sonoridade peculiares à voz.

\section{Sistemas de Classificação}

A rugoscopia palatina, como sistema de classificação, foi primeiramente proposta por Trobo-Hermosa ${ }^{27}$ e, nos anos seguintes, várias formas de classificação foram sugeridas ${ }^{25}$. Na classificação de Trobo-Hermosa ${ }^{27}$, as rugas são divididas em dois grupos: Simples (classificadas de $\mathrm{A}$ a $\mathrm{F}$ ) e Composta (resultantes da união de duas ou mais rugas), conforme exposto na Tabela 1.

Tabela 1 - Sistema de Classificação proposto por TroboHermosa $^{27}$

\begin{tabular}{c|c}
\hline Classificação & Tipo de Ruga \\
\hline Tipo A & Ponto \\
\hline Tipo B & Linha \\
\hline Tipo C & Curva \\
\hline Tipo D & Ângulo \\
\hline Tipo E & Sinuosa \\
\hline Tipo F & Círculo \\
\hline
\end{tabular}

Carrea $^{5}$ considerou quatro tipos principais de rugas palatinas, de acordo com a direção,
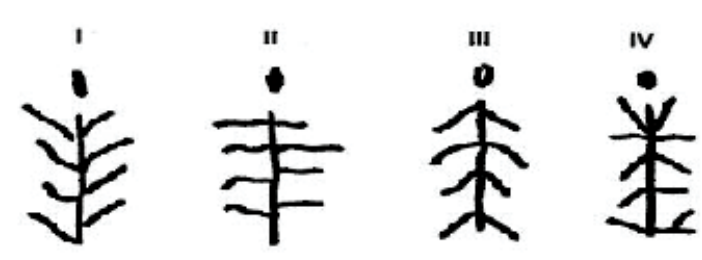

Figura 1 - Sistema de Classificação proposto por Carrea ${ }^{5}$. Desenho das rugas adaptado a partir da imagem disponível em www.pericias-forenses.com.br.

Martins-dos-Santos ${ }^{29}$ facilitou a caracterização individual rugoscópica de um indivíduo, ao dividir as rugas palatinas, conforme a sua localização (Figura 2). Dessa forma, para fins de classificação, as cristas da porção mais anterior se designam pelas letras iniciais das figuras $(P, R, C, A, C f, S, B, T$, $\mathrm{Q}, \mathrm{An})$, e as cristas de qualquer outra posição, por números (de 0 a 9) (Tabela 2).

Tabela 2 - Sistema de Classificação proposto por Martinsdos-Santos 29

\begin{tabular}{c|c|c}
\hline Figura & $\begin{array}{c}\text { Na posição } \\
\text { mais anterior }\end{array}$ & $\begin{array}{c}\text { Em outras } \\
\text { posições }\end{array}$ \\
\hline Ponto & $\mathrm{P}$ & 0 \\
\hline Reta & $\mathrm{R}$ & 1 \\
\hline Curva & $\mathrm{C}$ & 2 \\
\hline Ângulo & $\mathrm{A}$ & 3 \\
\hline Curva fechada & $\mathrm{Cf}$ & 4 \\
\hline Sinuosa & $\mathrm{S}$ & 5 \\
\hline Bifurcada & $\mathrm{B}$ & 6 \\
\hline Trifurcada & $\mathrm{T}$ & 7 \\
\hline Quebrada & $\mathrm{Q}$ & 8 \\
\hline Anômala & $\mathrm{An}$ & 9 \\
\hline
\end{tabular}

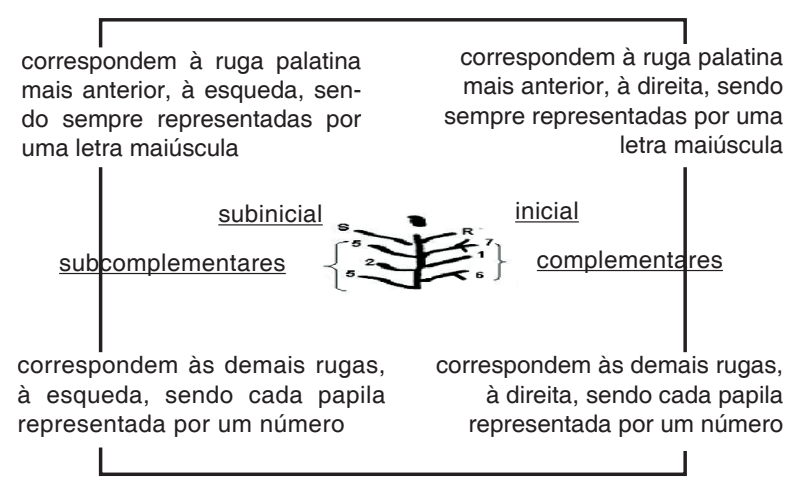

Figura 2 - Sistema de Classificação proposto por Martins-dosSantos $^{29}$ 
Tornavoi DC, Silva RHAD. Rugoscopia palatina e a aplicabilidade na identificação humana

dividindo a ficha rugoscópica em duas seções correspondentes às rugas encontradas à direita e à esquerda, ambas separadas por um traço vertical representativo da papila mediana ${ }^{16}$, conforme exposto na Figura 1.

Já Basauri $^{3}$ distingue as rugas principais (denominadas com letras) das acessórias (denominadas por números), conforme Tabela 3.

Tabela 3 - Sistema de Classificação proposto por Basauri ${ }^{3}$

\begin{tabular}{c|c|c}
\hline Ruga Principal & Ruga Acessória & Anatomia \\
\hline A & 1 & Ponto \\
\hline B & 2 & Linha \\
\hline C & 3 & Ângulo \\
\hline D & 4 & Sinuosa \\
\hline E & 5 & Curva \\
\hline F & 6 & Círculo \\
\hline X & 7 & Polimórfica \\
\hline
\end{tabular}

E Cormoy $^{7}$ elaborou sistema que classifica as rugas palatinas de acordo com as suas dimensões em três categorias: Ruga principal (acima de $5 \mathrm{~mm}$ ); Ruga acessória (variando de 3 a $4 \mathrm{~mm}$ ); Fragmentos (com menos de $3 \mathrm{~mm}$ ). Aliado com a forma em Linha, Curva e Angulada. A origem, a direção de cada ruga e a possibilidade de ramificações também são apontadas.

\section{ANÁlise dAS RUGAS PALATINAS}

Existem várias formas de avaliar as rugosidades palatinas, sendo a inspeção intra-oral a mais utilizada, devido à facilidade e ao baixo custo ${ }^{4}$. No entanto, esta maneira de análise poderá criar dificuldades se, no futuro, houver a necessidade de realizar um exame comparativo. Dessa forma, algumas técnicas podem ser realizadas durante o atendimento odontológico, de modo que se possam preservar provas que facilitem uma análise comparativa, visto que a identificação visual e o uso de impressões digitais são limitadas após a morte devido às mudanças associadas ao tempo, temperatura e umidade ${ }^{19}$.

A classificação das rugas palatinas pode ser realizada através de modelos de gesso. Nesta técnica, são feitas moldagens com alginato ou outro material similar, de modo a obter os modelos de gesso do arco superior do sujeito. As rugas são contornadas com a grafite de uma lapiseira de forma a serem evidenciadas. Em seguida, realizase a fotocópia do modelo em folha de papel A4, que será arquivada junto com a identificação do sujeito e a respectiva classificação rugoscópica ${ }^{22}$.

Outra técnica é por meio de fotografia do palato, obtida com utilização de câmera fotográfica e espelho intra-oral, estando o sujeito sentado e posicionando o espelho com a mão embaixo do mesmo, dentro da boca, para que as rugas palatinas sejam refletidas. O cirurgião-dentista posiciona-se a sua frente e fotografa a imagem refletida no espelho, que será enantiomorfa, sendo armazenada junto ao prontuário odontológico ${ }^{23}$.

ILUSTRAÇÃO DA CLASSIFICAÇÃO DE DIFERENTES SISTEMAS RUGOSCÓPICOS

Na Figura 3, apenas para fins didáticos, são demonstrados alguns dos sistemas de classificação citados.

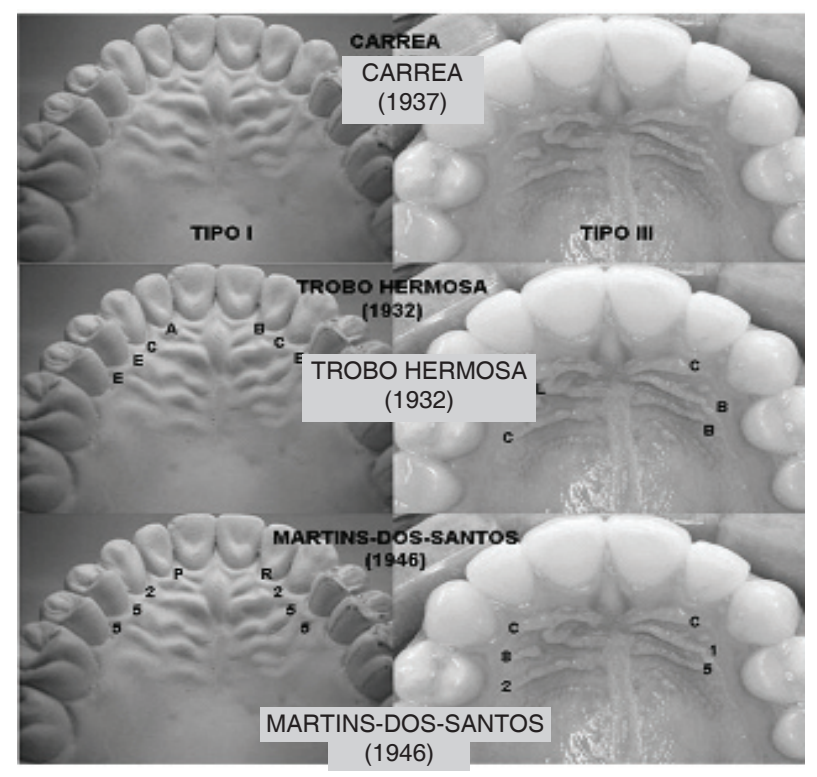

Figura 3 - Ilustração da classificação de diferentes sistemas rugoscópicos

\section{CONSIDERAÇÕES FINAIS}

Verifica-se que há a possibilidade de utilização das rugas palatinas no processo de identificação humana, tendo em vista que a configuração, 
Tornavoi DC, Silva RHAD. Rugoscopia palatina e a aplicabilidade na identificação humana

comprimento, largura, número e orientação variam consideravelmente entre as pessoas, além de sua resistência à decomposição. Os métodos aqui ilustrados apenas variam em sua forma de classificação, mas todos são aplicáveis na identificação humana, tanto no que se refere à classificabilidade quanto na individualidade, caso exista um registro prévio.

Tornavoi DC, Silva RHAD. Palatal rugae and applicability in human identification in forensic dentistry: literature review. Saúde, Ética \& Justiça. 2010;15(1):36-42.

AвstRAct: The palatine ridges are formed in the 3rd month of intrauterine life and remain in the same position throughout life, possessing resistance to destructive action, once covered by dental and skeletal structures. With a large anatomical variability, the palatine ridges are asymmetric in human species, making these distinctive in comparison to other mammals. Their ridges also present unique, unchanging, perennial and classifiable traits, which are fundamental requirements for human identification, being an alternative method when the classically established ones are not viable. This Forensic Anthropology resource got several techniques and systems of classification; its application is viable in both fresh corpses and living individuals. Therefore, this study presents the importance and the existing assorted classification systems through a literature review. It was concluded that using the identification technique through the roughness palate is feasible, but in spite of being simple and not requiring any complex instrumentation, it is not commonly known among professionals.

KEY WORDS: Forensic dentistry; Rugae palatal; Human identification; Forensic anthropology.

\section{REFERÊNCIAS}

1. Bansode SC, Kulkarni MM. Importance of palatal rugae in individual identification. J Forensic Dent Sci 2009;1(2):77-81.

2. Barbieri AM, Agostini R, Naressi SCM, Francesquini-Júnior L, Daruge-Júnior E. A identificação humana pela rugoscopia palatina em pacientes tratados com disjunção da maxila. Odontol Soc. 2008;10(1):8-9.

3. Basauri C. Forensic odontology and identification. Int Crim Police Rev. 1961;16:45-51.

4. Caldas IM, Magalhães $\mathrm{T}$, Afonso A. Establishing identity using cheiloscopy and palatoscopy. Forensic Sci Int. 2007;1:1-9.

5. Carrea JU. La identificacion humana por las rugosidades palatinas. Rev Orthodont. 1937;1:3-23.

6. Castellanos DCA, Higuera LFH, Avella AMH, Gutiérrez APP, Martinez JAC. Identificación positiva por medio del uso de la rugoscopia en un municipio de Cundinamarca (Colombia): Reporte de caso. Acta Odontol Venez. 2007;45(3):446-9.

7. Cormoy JP. La rugoscopie. Rev Chir Dentiste France. 1973;59-60.

8. Fávero F. Medicina legal. $12^{\mathrm{a}}$ ed. Belo Horizonte: Vila Rica; 1991.

9. França GV de. Medicina legal. Rio de Janeiro: Guanabara-Koogan; 2004.

10. Galvão LCC. Identificação médico-Legal através da ficha dentária anterior. Estudos médico-legais. Porto Alegre: Sagra-DC; 1996.

11. Gitto CA, Esposito SJ, Draper JM. A simple method of adding palatal rugae to a complete denture. J Prosthet Dent. 1999;81:237-9.

12. Gruber J, Kameyama MM. O papel da radiologia em odontologia legal: uma breve revisão. Pesq Odontol 
Tornavoi DC, Silva RHAD. Rugoscopia palatina e a aplicabilidade na identificação humana

Bras. 2001;15(3):263-8.

13 Jurado J, Martinz JM, Quengúan R, Martinez C, Moreno F. Analisis de rugas palatinas en jóvenes pertenecientes a dos grupos étnicos colombianos. Rev Estomatol. 2009;17(2):17-22.

14. Kapali S, Townsend G, Richards L, Parish T. Palatal rugae patterns in Australian aborigines and caucasians. Aust Dent J. 1997;42(2):129-33.

15. Limson KS, Julian R. Computerized recording of the palatal rugae pattern and an evaluation of its application in forensic identification. J Forensic Odontostomatol. 2004;22(1):1-4.

16. Martins-Filho IE. Simplificação de método para identificação humana por meio da rugoscopia palatina [dissertação]. Bauru: Faculdade de Odontologia de Bauru da Universidade de São Paulo; 2007.

17. Ohtani M, Nishida N, Chiba T, Fukuda M, Miyamoto $Y$, Yoshioka N. Indication and limitations of using palatal rugae for personal identification in edentulous cases. Forensic Sci Int. 2008;2(3):178-82.

18. Oliveira RN, Melani RF, Antunes JL, Freitas ER, Galvão LC. Contribuição da Odontologia Legal para a identificação post-mortem. Rev Bras Odontol.1998;55(2):117-22.

19. Patil MS, Patil SB, Achary AB. Palatine Rugae and their significance in clinical dentistry: a review of the literature. J Am Dent Assoc. 2008; 139(11):1471-8.

20. Rothwell BR. Principles of dental identification. Dent
Clin North Am. 2001;45(2):253-70.

21. Segovia AG. Rugoscopia: otra alternativa en la identificacion humana. Rev Exhumar. 2005; 2:49-51.

22. Sharma P, Saxena S, Rathod V. Comparative reliability of cheiloscopy and palatoscopy in human identification. Indian J Dent Res. 2009;20(4):453-7.

23. Silva RF, Daruge-Júnior E, Pereira SDR, Almeida SM, Oliveira RN. Identificação de cadáver carbonizado utilizando documentação odontológica: relato de caso. Rev Odont Ciên. 2008;23(1):90-3.

24. Silveira EMSZSF. Forensic dentistry: the importance of DNA to the examination by the experts. Saúde Ética Just. 2006;11(1/2):12-8.

25. Simas-Alves E. Medicina legal e deontologia. Curitiba: Edição do Autor; 1965.

26. Sopher IM. Forensic dentistry. Springfield: Charles C Thomas; 1976.

27. Trobo-y-Hermosa P. El aparato dentario del hombre prehistorico [dissertação]. Madrid: Universidade Complutense; 1932.

28. Van Der Linden FP. Changes in the position of posterior teeth in relation to rugae points. Am J Orthod. 1978;74(2):142-61.

29. Vanrell JP. Odontologia legal \& antropologia forense. Rio de Janeiro: Guanabara Koogan; 2002.

30. Warwick R, Williams PL. Gray anatomia. 35a ed. Rio de Janeiro: Guanabara Koogan; 1979.

Recebido em: 05/05/2010

Aprovado em: 04/06/2010 